Volume 8. No. 6, June 2020

International Journal of Emerging Trends in Engineering Research

Available Online at http://www.warse.org/IJETER/static/pdf/file/ijeter46862020.pdf

https://doi.org/10.30534/ijeter/2020/46862020

\title{
Improving the Properties of the Piston Surface by Optimized Nitriding Parameters
}

\author{
Tri Tjahjono ${ }^{1}$, Muhammad Hanief ${ }^{2}$, Mujiyono ${ }^{3}$, Suprapto $^{3}$, Tjipto Sujitno ${ }^{3}$, Tri Widodo Besar Riyadi ${ }^{1}$ \\ ${ }^{1}$ Faculty of Engineering, Universitas Muhammadiyah Surakarta, Surakarta 57162, Indonesia. \\ ${ }^{2}$ Faculty of Engineering, Universitas Negeri Yogyakarta, Yogyakarta 55281, Indonesia. \\ ${ }^{3}$ Badan Tenaga Atom Nasional, Yogyakarta 55281, Indonesia. \\ * Corresponding email: Tri.Riyadi@ums.ac.id
}

\begin{abstract}
Pistons of internal combustion engines are subjected to high fatigue loadings and high temperatures during operation. A progressive loss of the material may occur to the weakest areas of the piston resulting in a premature failure. A surface modification is required to lengthen its life. Nitriding is one of the surface treatments which can be used to enhance the surface properties. In this work, the processing parameters of nitriding process of the piston surface were investigated to to obtain the highest hardness. The optimized parameters were used to produce the treated product which subsequently tested using wear test, surface roughness test, and corrosion test. The samples were cut from a piston crown to form a $3 \mathrm{~mm}$ thickness and $13 \mathrm{~mm}$ width. The process of plasma nitriding was done in a DC glow discharge plasma nitriding machine with a flow of $\mathrm{N} 2$ gas. The processing parameters of the nitriding were pressures, time and temperature. The result shows that the highest hardness was obtained in the sample nitrided by a pressure of 1.2 mbar, a time of 3 hours, and a temperature of $175 \square \mathrm{C}$. However, the sample nitrided by the same parameters produces a highest value in the surface roughness and corrosion rate. The use of optimized parameters therefore can be used to lengthen the life of piston.
\end{abstract}

Key words: Aluminium piston, Corrosion, Hardness, Nitriding pressure, Nitriding temperature, Titriding time, Wear

\section{INTRODUCTION}

Aluminum alloys have been widely used in internal combustion engines [1,2]. This material can be used to replace cast iron and steel to reduce the weight of the engine and thereby reduce fuel consumption and emissions [3]. The piston is one of the most critical engine components which becomes the main driving component in the internal combustion engine $[4,5]$. The piston operates at very high thermal and mechanical loads and therefore it has to exhibit minimal tribological losses. In addition, the working pressure in the combustion chamber and the piston mechanical pressure produce thermal stress. As a result, piston parts can fail, for example due to damage to their surfaces [6]. Although the piston component has a cooling system through the piston ring, the relatively low melting point of $\mathrm{Al}$ alloy limited its operation. If there is heat dissipation at extreme temperatures it will endanger the piston components [7]. Thus, advance protection of the $\mathrm{Al}$ alloy in the piston component again the surface loads need to be carried out to achieve greater engine performance [8]. The surface modifications such as using coatings or surface treatments can be conducted [9-12]. Although there is a lot of research on piston systems, very few of them focus on improving surface properties for piston crowns.

Nitriding has been widely used to modify the surface properties by forming hard compound layers for some iron or aluminum alloys in order to increase surface hardness, wear resistance, and corrosion resistance [6,13]. Plasma nitriding is one of the surface treatment of metals by diffusion or deposition of nitrogen atoms in the form of ions into the metal surface, so that nitride compounds will be formed [14,15]. Plasma nitriding has great advantages because it has specific characteristics that are very useful for industrial development $[16,17]$.

Plasma can be defined as a collection of charged particles such as positively charged ions and negatively charged ions which is formed after a certain voltage difference exists. The free electrons hit the gas and cause the ionization process of the gas. In the plasma nitriding, the process of ionization of nitrogen atoms is done by utilizing the electron jump from free electrons given a high potential difference. The electrons move from the cathode to the anode leading to collision with nitrogen molecules between the two electrodes. This collision causes the nitrogen molecules to decompose and ionize. In DC plasma nitriding, the cathode is given by a negative potential and the anode is given by a positive potential. Nitrogen ions will enter the substrate through diffusion and will cause the structural changes in the substrate surface [18]. 
The gas particles produced from plasma in the form of $\mathrm{N}+$ hit metal surfaces causing the atoms on the metal surface to detach. Atoms on the metal surface will rejoin nitrogen gas atoms to form nitride molecular bonds. Nitride molecules will be deposited onto the metal surface and form a thin layer of nitride. At a certain temperature, the nitride compound will diffuse into the metal and fill in gaps or occupy existing vacancy positions. Therefore, the diffusion process of nitride atoms into metals depends on the temperature of the metal. When the temperature rises, the metal atom will vibrate and cause a greater distance between the atoms allowing the nitride atom to enter deeper between the atomic gaps. This will cause the nitride atom to be bonded more strongly. Based on the basic knowledge above, a tool that can meet the surface hardening process on metal materials by means of DC plasma was developed. With the right parameters of the nitriding process, a significant increase in surface hardness and tribological behavior can be achieved without a decrease in corrosion resistance.

The improvements of surface properties can be correlated with the formation of super-saturated interstitial nitrogen solid solutions in the distorted metal substrate [14]. The nitrogen saturation limits the nitride precipitation at a certain temperature, time and pressure [19]. Therefore, the insertion of nitrogen into the metal is a very interesting topic from the application view. In this work, the optimum parameter was observed to find the saturation point. The processing parameters of the nitriding process involve the pressure, time and temperature.

\section{METHODS}

The as-received sample was a piston crown obtained from commercial markets. The chemical composition of material (in wt.\%) was observed using an optical emission spectroscopy: Si: 0.181, Cu: 0.169, Mn: 0.042, Mg: 0.108, Cr: $0.549, \mathrm{Zn}: 0.752$, Ti: 0.012, Al: Balance. The cylindrical samples were cut from the as-received rod with $13 \mathrm{~mm}$ in diameter and $3 \mathrm{~mm}$ in thickness (see Figure 1). The samples were then ground using $\mathrm{SiC}$ grinding paper with sequential mesh size of 150, 220, 400, 800, 1000, 1200, 1500, 3000, and 5000. The surface of the sample was then polished using alcohol, cleaned in an ultrasonic cleaner for 30 minutes to remove any moisture content, and dried in hot air.

Plasma nitriding was carried out using a DC glow discharge plasma nitriding unit developed by PSTA BATAN Yogyakarta, with variation of pressures $(1.0,1.2,1.4$, and 1.6) mbar, times (1, 2, 3, and 4) hours, and temperatures $(1125,150,175$, and 200) $\square \mathrm{C}$. The microhardness of the nitrided products were evaluated with a Vickers indenter under a load of $10 \mathrm{gf}$ for 10 second indentation time. The microhardness values reported in this work was the average of five readings taken in varied positions. The tribological behaviors of the nitrided and untreated samples were determined with Ogoshi High Speed Universal Testing Machine (Type OAT-U) [20].

The tested samples have a diameter of $30 \mathrm{~mm}$ and a thickness of $10 \mathrm{~mm}$. The wear tests were carried out under a load of 2.12 $\mathrm{kg}$, with a disc revolution of $1430 \mathrm{rpm}$ for a distance of $90 \mathrm{~m}$. The gear ratio was $70 / 40$. The surface roughness test was conducted using a TR 200 surface roughness tester with accuracy of $0.001 \mu \mathrm{m}$, range of $40 \mu \mathrm{m}$, and weight $480 \mu \mathrm{m}$. The corrosion behavior was evaluated by electrochemical method. The formula used to calculate the corrosion rate is taken from Faraday's law as given in equation (1), where $r=$ wear rate $\mathrm{mm} /$ year or mmpy), $a=$ atomic weight $(\mathrm{gram} / \mathrm{mol})$, $\mathrm{I}=\mathrm{Icorr}=$ current density $(\mu A / \mathrm{cm} 2), k=$ constant 0.129 for mpy, and $n=$ number of electron.

$$
\text { Corrosion rate }(r)=k(a l / \pi D)
$$

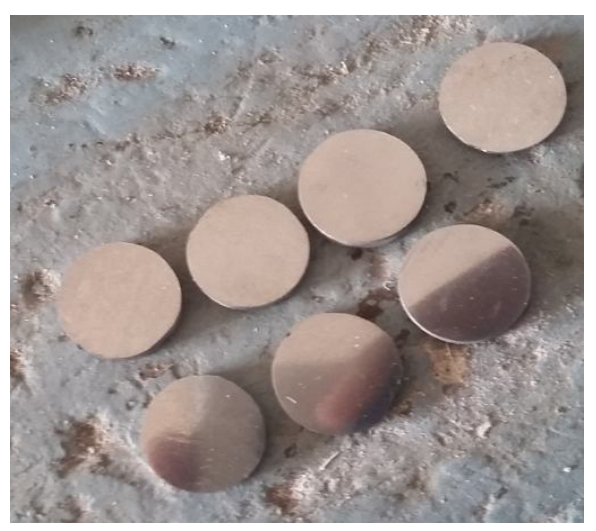

Figure 1: The samples taken from piston crown before nitriding.

\section{RESULT AND DISCUSSION}

\subsection{Hardness Optimization}

The hardness of the aluminum surface undergoing a nitriding process with a pressure difference is influenced by the amount of gas molecules inserted into the reactor tube. The more ideal levels of gas molecules inserted into the reactor tube are reached, the more hardness is obtained. By adding the gas pressure to the nitriding chamber, it can increase the number of deposited and diffused atoms of nitrogen. Figure 2(a) shows the information of hardness on the samples before and after nitriding process by pressures of 1.0 mbar, 1.2 mbar, 1.4 mbar and 1.6 mbar, with a fixed parameter of temperature at $175 \square \mathrm{C}$ and a time of 3 hours.

The result shows that the hardness of all nitrided samples are higher than that of untreated samples. This indicates that the nitriding process has increased the surface hardness of the 
sample. The variation of nitriding pressures, initially gives an increase hardness in the pressure between 1.0 mbar and 1.2 mbar. This is due to the condition when the pressure gets higher, the density of ionized and deposited nitrogen atoms on the surface of the material increases. The product hardness then decreases in the pressure between 1.2 mbar and 1.6 mbar. This is possible because the aluminum alloy material has a saturated phase which is caused by the deposition rate being greater so that there is no equilibrium between the deposition rate and the diffusion of nitrogen atoms in the aluminum surface. This condition is caused by the accumulation of nitrogen atoms on the surface because the deposition rate is greater than the diffusion rate. At a pressure of $1.2 \mathrm{mbar}$, the highest hardness of product was obtained. This is possible because at a pressure of $1.2 \mathrm{mbar}$ an equilibrium occurs between nitrogen atoms which are deposited at a diffusion rate and forms aluminum nitride compounds on the surface of the material. Judging from these results, it can be said that the pressure of 1.2 mbar is the optimum pressure for the nitriding process with a temperature of $175 \square \mathrm{C}$ and a time of 3 hours.

Further hardness test was carried out using a variation of time with 1 hour, 2 hours, 3 hours, and 4 hours. Whereas, the nitriding pressure and temperature were set in a fixed condition at 1.2 mbar and $175 \square \mathrm{C}$, respectively. Investigation with time variation was used to find the optimal time of the nitriding process in order to produce the maximum hardness in the surface of the nitride layer. In general, the higher the operating time, the more gas is introduced into the plasma reactor chamber so that there is higher number of nitrogen atoms can be ionized and deposited into the nitride surface.

The hardness test conducted with the time variation is shown in Figure 2(b). The result shows that the hardness of the nitrided product processed by nitriding time from 1 hour to 2 hours was increased. The longer time of nitriding process may increase the density of ionized nitrogen atoms which subsequently deposited on the surface of the material. Whereas the hardness of the product nitrided by times of 3 hours and 4 hours was decreased. This can be made possible because the surface of the aluminum surface has a saturated condition due to equilibrium between the deposition rate and the diffusion of nitrogen atoms in the aluminum alloy. The accumulation of nitrogen atoms on the surface then causes the deposition rate to be greater than the diffusion rate.

The final hardness test was carried using a variation of temperature with $125{ }^{\circ} \mathrm{C}, 150{ }^{\circ} \mathrm{C}, 175{ }^{\circ} \mathrm{C}$, and $200{ }^{\circ} \mathrm{C}$. Whereas, the nitriding pressure and time were set in a fixed condition at 1.2 mbar and $175 \square \mathrm{C}$, respectively. The hardness test conducted with the temperature variation is shown in Figure 2(c). The result shows that all the nitride samples produces higher hardness than that of the untreated sample.
The highest hardness of the product was achieved in the nitriding temperature at $175^{\circ} \mathrm{C}$. This is possible because the nitrogen atoms deposited on the surface are still small and the substrate is not saturated yet so the substrate can still accept nitrogen atoms to form aluminum nitride compounds. If the nitriding temperature is added to a temperature of $200^{\circ} \mathrm{C}$ and $225^{\circ} \mathrm{C}$, the hardness of product decreases. This is due to the addition of nitrogen atoms into the interstitial position so the hard phase is shifted to the soft phase or the $\mathrm{N}$ atoms only collided the surfaces and cannot diffuse into the substrate.

Based on the results of the hardness tests as given in Figure 2(a), (b) and (c) of the nitrided products carried out with variations of nitriding pressure, time and temperature, it can be stated that the optimum parameter used to form a highest hard nitride layer on the aluminum piston at $138.22 \mathrm{HV}$ was achieved by processing parameters using nitriding pressure of 1.2 mbar, nitriding time of 2 hour, and nitriding temperature at $175^{\circ} \mathrm{C}$ temperature. This hardness was higher than that of untreated sample which has an initial hardness of $56.46 \mathrm{HV}$.
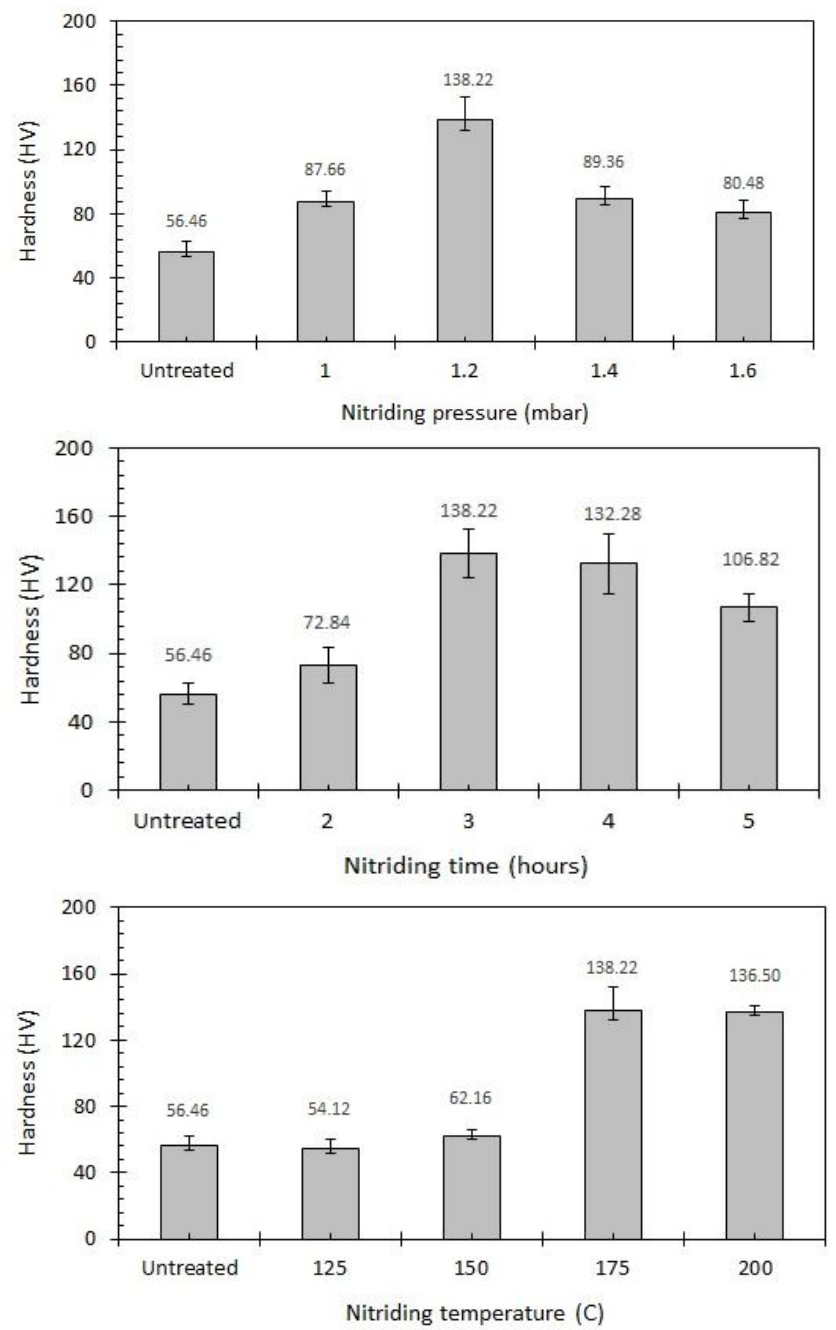

Figure 2: Hardness of untreated and treated sample using a variation of: (a) pressure, (b) time, and (c) temperature. 
Tri Tjahjono et al., International Journal of Emerging Trends in Engineering Research, 8(6), June 2020, 2490 - 2495

\section{Wear Rate}

A wear test was carried out on the surface of the samples without nitriding treatment and with nitriding treatment with pressure variations of $1 \mathrm{mbar}, 1.2 \mathrm{mbar}, 1.4 \mathrm{mbar}$, and 1.6 mbar. Whereas, the parameter of time and temperature were fixed at 2 hours and $175 \square \mathrm{C}$, respectively. The result of wear tests that calculated with equation (1) is shown in Figure 3. The result shows that the untreated sample has a wear rate of $0.000989918 \mathrm{~mm}^{2} / \mathrm{kg}$. The sample nitrided by a pressure of 1 mbar has a much smaller wear rate compared to that of the untreated sample. However, the lowest wear rate was obtained in the sample nitrided by a pressure of 1.2 mbar. This indicates that the nitride compounds was optimally formed in the surface at a pressure of $1.2 \mathrm{mbar}$. This result can be related to the highest hardness of the nitrided product. Further increase of pressure to $1.4 \mathrm{mbar}$ and $1.6 \mathrm{mbar}$ increases the wear rate to $0.000880034 \mathrm{~mm}^{2} / \mathrm{kg}$, and $0.00113967 \mathrm{~mm}^{2} / \mathrm{kg}$, respectively. This may indicate that the material has experienced a saturation point so that it is easier to wear out [21]. Taking into account the wear rate and the hardness obtained previously, it can be said that the nitriding process achieved an optimized conditions at a pressure of $1.2 \mathrm{mbar}$, a time of 2 hours, and a temperature of $175{ }^{\circ} \mathrm{C}$. Other researchers have considered materials properties related to wear [22,23] and contributing to failure [24].

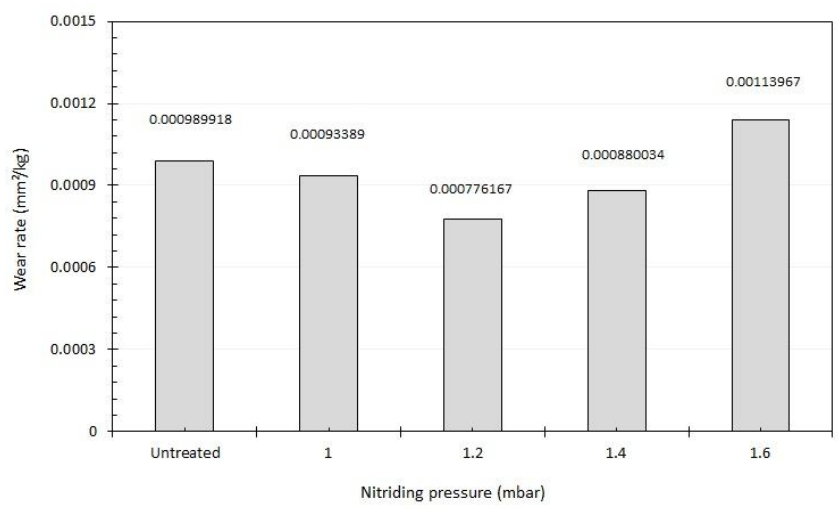

Figure 3: Wear rate of untreated and treated products with different nitriding pressures.

\subsection{Surface Roughness}

The results of surface roughness testing on the samples before and after plasma nitriding can be seen in Figure 4. The tested samples for the surface roughness are taken from the untreated sample and the treated samples which nitrided by variations in pressures of $1 \mathrm{mbar}, 1.2 \mathrm{mbar}, 1.4 \mathrm{mbar}$, and 1.6 mbar. The parameter of time and temperature were fixed at 2 hours and $175 \square \mathrm{C}$, respectively. The relationship between the nitriding process and the surface roughness of the samples is shown in Figure 6. The result shows that the surface roughness of the untreated material was $0.2329 \mu \mathrm{m}$, whereas the surface roughness the sample treated by nitriding pressure of $1 \mathrm{mbar}$ is $0.3013 \mu \mathrm{m}$, which is just a little higher than that of the untreated sample.

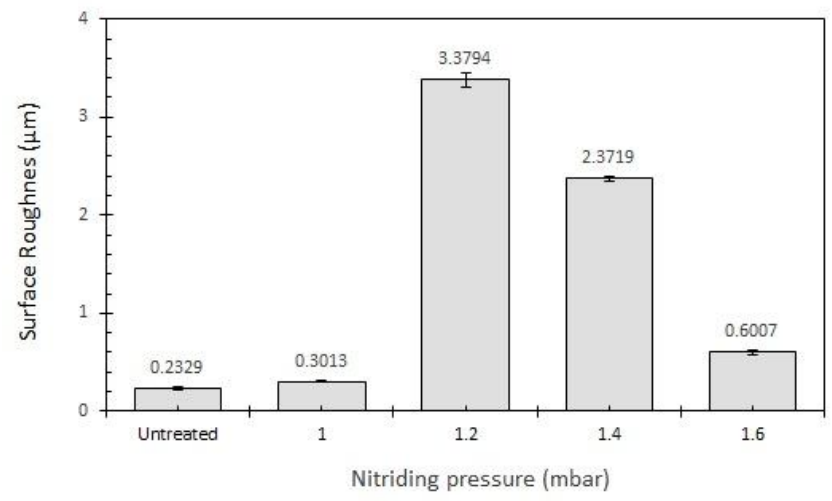

Figure 4: Surface roughness of untreated and treated products with different nitriding pressures.

The surface roughness of the sample nitrided by with a pressure of 1.2 mbar, however, has a dramatic increase to a value of $3.3794 \mu \mathrm{m}$. Further increase of the nitriding pressure with 1.4 mbar and 1.6 mbar reduces the surface roughness to $2.33719 \mu \mathrm{m}$ and $0.6007 \mu \mathrm{m}$, respectively. From these results it can be said that the best surface roughness was obtained in the nitriding process with a pressure parameter of $1 \mathrm{mbar}$. This might be due to the low nitriding pressure had produced nitride particle with more evenly distributed.

\section{Corrosion Rate}

Corrosion test was carried out on the untreated and treated samples by electrochemical methods. The used treated samples were obtained by the sample which nitrided by pressures of $1 \mathrm{mbar}, 1.2 \mathrm{mbar}, 1.4 \mathrm{mbar}$ and $1.6 \mathrm{mbar}$, where the nitriding time and temperature were maintained at 2 hours and $175^{\circ} \mathrm{C}$, respectively. The corrosion test in the form of current density is given in Table 1. Using the current density, the corrosion rate was calculated based on the equation (1), and the result is shown in Figure 5. The untreated material shows a current density of $226.470 \mu \mathrm{A} / \mathrm{cm}^{2}$ with a corrosion rate of $140.76 \mathrm{mpy}$. An increase of the pressure with $1 \mathrm{mbar}$ and $1.2 \mathrm{mbar}$ increases the current density, which is greater than that of the untreated material. Using a pressure of $1.4 \mathrm{mbar}$, the current density decreases to $182,700 \mu \mathrm{A} / \mathrm{cm}^{2}$ with a corrosion rate of $113.54 \mathrm{mpy}$.

Table 1: Result of The Corrosion Test

\begin{tabular}{|c|c|c|}
\hline Sample no. & $\begin{array}{c}\text { Pressure } \\
\text { (mbar) }\end{array}$ & Fullname \\
\hline 1 & Untreated & 226.470 \\
\hline 2 & 1.0 & 243.860 \\
\hline 3 & 1.2 & 337.500 \\
\hline 4 & 1.4 & 171.090 \\
\hline 5 & 1.6 & 157.040 \\
\hline
\end{tabular}


Tri Tjahjono et al., International Journal of Emerging Trends in Engineering Research, 8(6), June 2020, 2490 - 2495

Furthermore, at a pressure of 1.6 mbar, the current density gets reduced to $157,040 \mu \mathrm{A} / \mathrm{cm}^{2}$ with a corrosion rate of 97.6 mpy. Based on these results, the best material resistance to the corrosion was achieved in the nitriding process with a pressure parameter of 1.6 mbar. It may be said that the use of 1.6 mbar in pressure has produced a thick nitride layer so when the oxide that wants to enter the material becomes blocked. In the nitriding process with a pressure of $1.2 \mathrm{mbar}$ the material becomes easily corroded which may be due to the material has been soft so the oxide that wants to enter the material becomes easier. From the obtained results, there is a relationship that the greater the value of the current density (Icorr), the more the corrosion rate is. Vice versa, the smaller the current density (Icorr), the more the corrosion rate is obtained. Comparing all the samples, the lowest corrosion rate is 97.6 mpy with a current density of $157,040 \mu \mathrm{A} / \mathrm{cm}^{2}$, which was obtained in the plasma nitriding process with a pressure of $1.6 \mathrm{mbar}$, a time of 2 hours and a temperature of $175^{\circ} \mathrm{C}$.

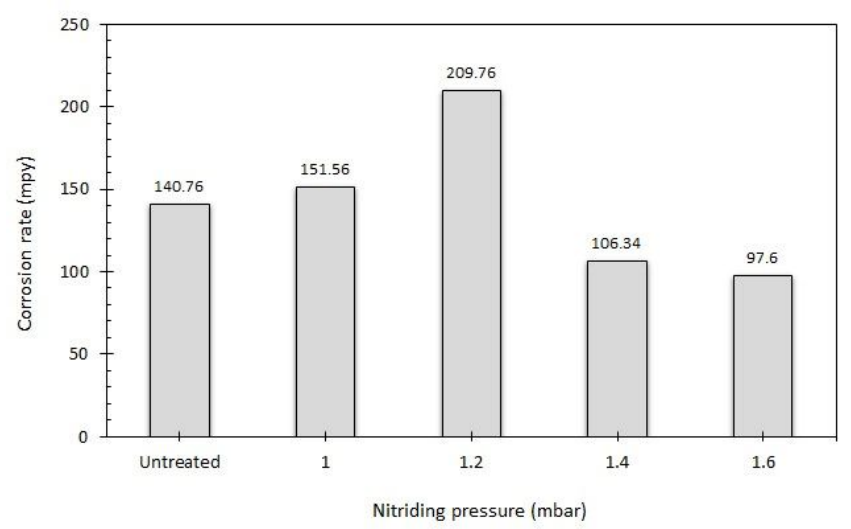

Figure 5: Corrosion rate of untreated and treated products with different nitriding pressures.

\section{CONCLUSION}

This work has been successfully carried out to study the effect of the pressure, time, and temperature of the plasma nitriding on the hardness, wear resistance, surface roughness, and corrosion resistance of the aluminum piston. The optimum parameters of pressure, time, and temperature for the plasma nitriding to produce the highest hardness were obtained at 1.2 mbar, 3 hours, and $175^{\circ} \mathrm{C}$, with a maximum hardness value of 138.22 HV. The same parameters, however, produce highest surface roughness and corrosion rate. The plasma nitriding process has successfully used to study the improvement of the surface properties such as surface hardness, wear resistance, surface roughness, and corrosion resistance of the aluminum piston.

\section{ACKNOWLEDGEMENT}

The authors would like to thank the Directorate General of Research and Development Strengthening, The Ministry of
Research, Technology and Higher Education of the Republic of Indonesia, with research grant No.: T/140/E3/RA.00/2019 and contract Number: 199.45/A.3-III/LPPM/V/2019.

\section{REFERENCES}

1. Z. Yao, and W. Li. Microstructure and thermal analysis of APS nano PYSZ coated aluminum alloy piston, Journal of Alloys and Compounds, 812, 152162, 2020. https://doi.org/10.1016/j.jallcom.2019.152162

2. J. Chen, X. Zhou, W. Wang, B. Liu, Y. Lv, W. Yang, Y. Liu. A review on fundamental of high entropy alloys with promising high-temperature properties, Journal of Alloys and Compounds, 760, 15-30, 2018. https://doi.org/10.1016/j.jallcom.2018.05.067

3. L. Kerni, A. Raina, and M.I.U. Haq. Performance evaluation of aluminium alloys for piston and cylinder applications, Materials Today: Proceedings, 5(9), 18170-18175, 2018.

https://doi.org/10.1016/j.matpr.2018.06.153

4. G. Sivakumar, and S.S. Kumar. Investigation on effect of Yttria Stabilized Zirconia coated piston crown on performance and emission characteristics of a diesel engine, Alexandria Engineering Journal, 53(4), 787-794, 2014.

https://doi.org/10.1016/j.aej.2014.08.003

5. K. Taherkhani, and M. Soltanieh. Composite coatings created by new method of active screen plasma nitriding on aluminium alloy 6061, Journal of Alloys and Compounds, 741, 1247-1257, 2018. https://doi.org/10.1016/j.jallcom.2017.12.360

6. A.S. Khusainov, and A.A. Glushchenko. Theoretical Prerequisites for Lowering Piston Temperature in Internal Combustion Engines, Procedia Engineering, 150, 1363-1367, 2016. https://doi.org/10.1016/j.proeng.2016.07.330

7. G. Nicoletto, E. Riva, and A. Di Filippo. High temperature fatigue behavior of eutectic al-si- Alloys used for piston production, Procedia Engineering, 74, 157-160, 2014. https://doi.org/10.1016/j.proeng.2014.06.241

8. N.Y. Dudareva, R.D. Enikeev, and V.Y. Ivanov. Thermal Protection of Internal Combustion Engines Pistons, Procedia Engineering, 206, 1382-1387, 2017. https://doi.org/10.1016/j.proeng.2017.10.649

9. G. Da Silva Savonov, M.G.G. Camarinha, L.O. Rocha, M.J.R. Barboza, G.V. Martins, and D.A.P. Reis. Study of the influence of the RRA thermal treatment and plasma nitriding on corrosion behavior of 7075-T6 aluminum alloy, Surface and Coatings Technology, 374, 736-744, 2019. https://doi.org/10.1016/j.surfcoat.2019.04.095

10. T.W.B. Riyadi, T. Tjahjono, B.R.Utomo, Sarjito, Irianto, Suprapto, and T. Sujitno. Effect of sputtering times on the properties of $\mathbf{N i C r}-\mathrm{Al}$, In AIP Conference Proceedings, 1977(1), 020031, June 2018. https://doi.org/10.1063/1.5042887 
11. A.S. Darmawan, T.W.B. Riyadi, A. Hamid, B.W. Febriantoko, and B.S. Putra. Corrosion resistance improvement of aluminum under anodizing process, AIP Conference Proceedings, 1977(1) 020006, June 2018. https://doi.org/10.1063/1.5042862

12. T.W.B. Riyadi, and Masyrukan. Hardness and wear properties of laminated $\mathrm{Cr}-\mathrm{Ni}$ coatings formed by electroplating, In AIP Conference Proceedings, 1831, April 201. https://doi.org/10.1063/1.4981175

13. J. Miyamoto, and P. Abraha. The effect of plasma nitriding treatment time on the tribological properties of the AISI H13 tool steel, Surface and Coatings Technology, 375, 15-21, 2019. https://doi.org/10.1016/j.surfcoat.2019.07.001

14. E. Ura-Bińczyk, A. Krawczyńska, R. Sitek, and M. Lewandowska. Mechanical properties and corrosion resistance of hydrostatically extruded 316 LVM stainless steel after low-temperature plasma nitriding, Surface and Coatings Technology, 375, 565-572, 2019. https://doi.org/10.1016/j.surfcoat.2019.07.035

15. J.W. Yao, F.Y. Yan, M.F. Yan, Y.X. Zhang, D.M. Huang, and Y.M. Xu. The mechanism of surface nanocrystallization during plasma nitriding, Applied Surface Science, 488, 462-467, 2019. https://doi.org/10.1016/j.apsusc.2019.05.164

16. C.E. Pinedo. The use of selective plasma nitriding on piston rings for performance improvement, Materials and Design, 24(2), 131-135, 2003. https://doi.org/10.1016/s0261-3069(02)00121-8

17. A.P. de Andrade Manfridini, G.C.D. de Godoy, and L. de Arruda Santos. Structural characterization of plasma nitrided interstitial-free steel at different temperatures by SEM, XRD and Rietveld method, Journal of Materials Research and Technology, 6(1), 65-70, 2017.

https://doi.org/10.1016/j.jmrt.2016.07.001
18. A. Ababneh, U. Schmid, J. Hernando, J.L. Sánchez-Rojas, and H. Seidel. The influence of sputter deposition parameters on piezoelectric and mechanical properties of AIN thin films, Materials Science and Engineering: B, 172(3), 253-258, 2010. https://doi.org/10.1016/j.mseb.2010.05.026

19. M.M. Haque, and M.A. Maleque. Effect of process variables on structure and properties of aluminium Silicon piston alloy, Journal of Materials Processing Technology, 300(3-4), 122-128, 1998. https://doi.org/10.1016/s0924-0136(97)00409-3

20. W. Winarto, D. Priadi, N. Sofyan, and A. Wicaksono. Wear Resistance and Surface Hardness of Carbon Nanotube Reinforced Alumina Matrix Nanocomposite by Cold Sprayed Process, Procedia Engineering, 170, 108-112, 2017. https://doi.org/10.1016/j.proeng.2017.03.020

21. H.E.L. Ramos, A.R. Franco, and E.A. Vieira. Influence of plasma nitriding pressure on microabrasive wear resistance of a microalloyed steel, Journal of Materials Research and Technology, 8(2), 1694-1700, 2019. https://doi.org/10.1016/j.jmrt.2018.07.025

22. M. Bhandari, Mechanical Computations of Functionally Graded Material Plate Subjected to Transverse Load, International Journal of Emerging Trends in Engineering Research, 8(4), 969 - 974, 2020. https://doi.org/10.30534/ijeter/2020/13842020

23. V. A. Ivanov, Wear Resistance of Repair Composite Materials with Ceramic Fillers, International Journal of Emerging Trends in Engineering Research, 8(4), 1192 $-1195,2020$. ttps://doi.org/10.30534/ijeter/2020/39842020

24. A.E. Ismail and A.F. Mat Beyi, A Brief of Sources of injury and failure during stent implantation, International Journal of Emerging Trends in Engineering Research, 8(3), 667- 673, 2020. https://doi.org/10.30534/ijeter/2020/10832020 